\title{
A INFLUÊNCIA DO DIREITO NATURAL E DA FILOSOFIA NAS DECISÕES JUDICIAIS
}

TREVISANI, Renato Cesar ${ }^{1}$

RESUMO: Devo confessar que desde a época de acadêmico vislumbro a incidência de elementos extraídos do Direito Natural e da Filosofia nas mais variadas decisões judiciais. E isto pode ser observado em todos os ramos desta frondosa árvore que é o direito. Assim, nota-se que eles têm ocupado um espaço que sempre lhes pertenceram em todas as áreas, embora ainda com certa timidez. Acrescento, também, por muito oportuno, que a Ética sempre teve sua cota parte de contribuição eis que fundada em valores que não enfrentam crises, valores que independem do tempo e do lugar em que se apresentam. E por acreditar que o jurisdicionado deve receber uma atenção individualizada e dedicada do Estado-Juiz qualquer que seja o resultado da demanda, tem-se que o uso constante dos elementos acima torna-se capaz de retomar o prestígio das instituições e o respeito à pátria.

Palavras-chave: Valores éticos. Jusnaturalismo. Moral.

\section{THE INFLUENCE NATURAL LAW AND PHILOSOPHY IN THE JUDGMENTAL DECISIONS}

SUMMARY: I shall confess that since the academic time I have glimmered the incidence of elements extracted from the Natural Law and Philosophy in the most varied judgmental decisions. And this can be observed in all branches of this leafy tree that is Law. Thus, it is possible to notice that they have taken a place that has always belonged to them in all areas, with some shyness though. Timely, I also add that Ethics has always had its quota share of contribution behold founded in values that do not face crises, values that are regardless of the time and place they are presented. And by believing that the court must receive an individualized and dedicated attention from the State-Court apart from the result of the lawsuit, I may say that the constant usage of the elements aforementioned, make it capable to recapture the prestige of institutions and respect to homeland. May the reader have the word.

Keywords: Ethical values. Jusnaturalism. Moral

\section{INTRODUÇÃO}

"Se, a princípio, a ideia não é absurda, então não há esperança para ela" - Albert Einstein (PENSADOR, [1879-1975?]).

Assim inicio esta modesta pretensão que se resume a demonstrar que as decisões judiciais devem receber o abrigo dos elementos fundados no Direito Natural e na Filosofia, estes em conjunto com a Ética, reduzindo as discussões de caráter técnico e ampliando aquelas de cunho filosófico por saber que numa sociedade que apresenta e experimenta valores tão convertidos resta aos Juízes a nobre e honrosa função de dizer o que é justo e o que é certo, eis que o Juiz quando sentencia estampa grande parte da formação que recebeu.

\footnotetext{
${ }^{1}$ Juiz; Mestre; Doutorando; Professor Universitário.
} 
E por acreditar que o Direito Natural e a Filosofa devem restar à frente de outros valores, posso afirmar que a aplicação de elementos éticos reúne condições de reavivar a crença nas instituições e fortalecer a esperança no futuro de qualquer Nação e pela condição social que o Judiciário pátrio ocupa, todos os seus integrantes estão legitimamente autorizados e convocados para este mister. Como dito, a sentença (do latim sententia) representa aquilo que o Julgador sentiu.

Para tanto, inicio com uma preocupação voltada à aplicação da justiça em todos os seus níveis, com destaque à qualidade da prestação jurisdicional. E por este estudo guardar uma especial e íntima relação com o cotidiano do Judiciário Trabalhista, vislumbro que será muito útil explorar esta questão acerca da tutela jurisdicional que é dirigida ao autor-trabalhador sabendo que, afinal, "o trabalho é a origem das coisas" (ROTARY, 2005).

Tem-se como muito comum a constatação do uso de manifestação judicial exageradamente técnica, às vezes até incompreensível para as partes por existir uma preocupação pelos operadores do direito, reservadamente ligada ao positivismo e sua exteriorização, o que resulta num modelo complexo, gessado e rígido.

Por meio de análise fundada no nosso sistema jurídico mediante uma criteriosa e detalhada observação de todas as etapas do modelo aplicado à solução das questões judiciais trabalhistas, notase lugar garantido para a melhora da prestação judicial, notadamente no que tange ao conteúdo das sentenças e decisões.

E por saber das limitações humanas, espero que futuros trabalhos neste sentido possam abordar e assim contribuir para o aprimoramento desta questão nuclear aqui exposta. E quando falo de Direito Natural, de Filosofia em conjunto com elementos éticos, reservo lugar aos princípios, estes que não se encontram em conflito ao contrário das normas e do Direito Positivo, diante das alterações sociais observadas, catalogadas de evolução.

Assim está a necessidade de se suavizar a norma posta e conhecida sem ferir o preceito, de se revelar o núcleo da mens legislatoris, tendo em vista que o direito deve servir à realidade, sob pena desta se vingar e não servir ao direito. Neste particular, as lições de Wittgenstein ${ }^{2}$ dão conta de que "o direito é sendo", visto que a dinâmica capaz de tudo envolver de há muito desafia uma ruptura com a tradição exacerbada do medo daquilo que é novo, sempre ao saber que o direito deve ser estável jamais estático.

Concluindo esta etapa de apresentação, pretendo registrar que nos dias de hoje pesquisa alguma parte da estaca zero, mesmo que exploratória, isto é, de avaliação de uma situação concreta desconhecida em um dado local. Resta certo que alguém ou um grupo, em algum lugar e de qualquer forma possível, já deve ter feito pesquisas iguais ou semelhantes, ou mesmo complementares de certos aspectos deste estudo. Neste passo, uma busca por fontes documentais, bibliográficas ou jurídicas, torna-se imprescindível para que não haja eventual duplicação de esforços.

\section{DIREITO NATURAL}

Uma observação fundada na criação e no funcionamento de civilizações que por muito tempo predominaram tanto pelas suas estruturas físicas, abrangência, bem como pelos seus poderios

\footnotetext{
${ }^{2}$ Ludwig Joseph Johann Wittgenstein foi um filósofo austríaco, naturalizado britânico, um dos principais atores da virada linguística na filosofia do século XX. Suas principais contribuições foram feitas nos campos da lógica, filosofia da linguagem, filosofia da matemática e filosofia da mente (WIKIPEDIA, 2014).
}

Nucleus, v.11, n.1, abr.2014 
intelectuais, dá conta do uso do Direito Natural, este que está voltado ao homem e tem sua origem insculpida como essência no próprio homem. Daí a expressão "natural".

Hugo Grócio ${ }^{3}$, catalogado por alguns como o pai do Direito Natural, ao laicizar essa fração do direito, afirmou que: "O Direito Natural existiria mesmo que Deus não existisse ou que, existindo, não cuidasse dos assuntos humanos" (NADER, 2003, p.368). Tem-se, portanto, que o Direito Natural sempre se mostrou muito influente e de forma constante nos grupos sociais. Os registros, guardadas as épocas de cada observação, dão conta de que ele integrava o dia a dia dos cidadãos regulando quase todas as relações pessoais o que ainda pode ser observado nos tempos atuais, embora de forma muito reduzida. Por tal importância, este ramo deve integrar a árvore frondosa do direito pelo fato, também, de sempre ter sido visto como algo inerente à natureza do homem.

O Direito Natural atua como modelo de patrimônio espiritual que o indivíduo recebe ao nascer e que se reforça mais ainda na condição de soberano e independente diante das fronteiras territoriais que extrapola bem como por não se contaminar pelos limites temporais que com ele não se comunicam. Embora perigosa a prática de conceituá-lo, ele pode ser traduzido na existência inequívoca de um direito fundado na origem das coisas, eis que enraizado na vontade do criador e assim permanece intimamente ligado no direito decorrente daquilo que é justo.

Destaque deve ser dado para o fato de que o Direito Natural, em oposição ao Direito Positivo, nunca esteve em ambiente de crise. Eventual fase de acomodação do primeiro requer uma adaptação porque se relaciona diretamente aos valores da vida. Atua como fundamento e legitimação do ordenamento jurídico construído pelas necessidades humanas e em segundo lugar, representa algo que intervém na interpretação e na integração das lacunas e na correção das normas jurídicas, sempre de forma natural, circunstância que o concretiza.

Uma ideia que se tem sobre a expressão Direito Natural (do latim ius naturali) ou jusnaturalismo, "pode ser fundamentada a partir da razão prática com o fim de distinguir o que não é razoável na prática do que é razoável, e, por conseguinte, o que é realmente importante de se considerar na prática em oposição ao que não o é" (FINNIS apud CANTO-SPERBER, 2003, p. 3642).

Neste ponto, uma característica fundamental e capaz de exteriorizar uma noção do Direito Natural é o seu próprio projeto. Note-se que ele não se propõe a uma descrição dos assuntos humanos por meio de uma teoria, tampouco procura alcançar o patamar de ciência social descritiva. Pelo contrário, o estudo que o envolve tem como escopo avaliar as opções humanas com o propósito de agir sempre de modo razoável e bem.

Esta linha de raciocínio abrange pensadores como Tomás de Aquino, Francisco Suárez, Richard Hooker, Thomas Hobbes, Hugo Grócio, Samuel Von Pufendorf, John Locke e Jean-Jacques Rousseau, que tiveram influência profunda no movimento do racionalismo jurídico do século XVIII, quando surge a noção dos direitos fundamentais, do conservadorismo e do desenvolvimento da common law. Isto foi alcançado através da fundamentação e manutenção de determinados princípios do Direito Natural que são considerados bens humanos imprescindíveis e evidentes em si mesmos.

Assim, como conclusão primeira tem-se que o Direito Natural ampara a existência última e acabada do direito catalogado de positivado. Em decorrência, torna-se mais compreensível e justificado ainda o seu enraizamento na filosofia que possibilita ao jurista valer-se da técnica de distinguir o direito na sua latência, considerado autêntico, do direito não disciplinador do homem

\footnotetext{
${ }^{3}$ Hugo Grócio, Hugo Grotius, Huig de Groot ou Hugo de Groot foi um jurista a serviço da República dos Países Baixos. Considerado o precursor do Direito Internacional baseando-se no Direito Natural. Foi também filósofo, dramaturgo, poeta e um grande nome da apologética cristã (WIKIPEDIA, 2014).
} 
como ser em suas relações sociais e finalidades, sem qualquer dicotomia no tocante a faculdade, ambas no aspecto jurídico.

Neste sentido a afirmação de que apesar de haver uma história das teorias, opiniões e doutrinas que sustentam a existência de princípios do Direito Natural, estes por si só, não possuem uma história. Academicamente mais completo seria falar numa trajetória de origens e sucessões do Direito Natural e suas variantes. Aliás, o Direito Natural prefere se afastar de pontos extremados como se dá com o uso da expressão "melhor". Mais recomendável dizer o mais completo ou a mais completa. Os princípios do Direito Natural valem e existem independentemente do seu uso ou do seu esquecimento, assim como os princípios matemáticos (SILLS, 2007).

Entretanto, a expressão "Direito Natural" não é criação aristotélica, pois já havia sido utilizada pelos sofistas (HERVADA, 2008, p. 337).

Na visão de Aristóteles, o Direito Natural tem duas características básicas: a primeira é de não se valer das opiniões humanas que em qualquer lugar tem a mesma força; a segunda é que junto dele aparece o justo legal relacionado ao Direito Positivo, sendo próprio desse direito provir da convenção humana, tendo como característica própria ser variável (HERVADA, 2008, p. 338).

O Cristianismo do Apóstolo Paulo de Tarso (WIKIPEDIA, 2014) registrou em sua Epístola aos Romanos, 2:14-15 (WIKIPEDIA, 2014), que: "Os pagãos, que não têm a lei, fazendo naturalmente as coisas que são da lei, embora não tenham a lei, a si mesmos servem de lei; eles mostram que o objeto da lei está gravado nos seus corações, dando-lhes testemunho a sua consciência, bem como os seus raciocínios, com os quais se acusam ou se escusam mutuamente."

E com este pensamento sobre o alcance da proteção a ser ofertada pelo Direito Natural, Thomas Jefferson menciona a expressão "direitos inalienáveis" na Declaração de Independência dos Estados Unidos: "Consideramos estas verdades como evidentes, que todos os homens são criados iguais, que seu Criador lhes concede certos direitos inalienáveis, que entre estes estão a Vida, a Liberdade e a busca da Felicidade"(WIKIPEDIA, [1776?]).

No sentido essencialmente metafísico do direito, apesar de divergentes opiniões, acredito que podemos disponibilizar, presumivelmente, a seguinte hierarquia, nesta ordem: Direito Natural, Ética, Moral e Direito Positivo.

A justificativa encontra amparo na afirmativa de que o Direito Natural corresponde a um sentir no mundo das ideias, afinal ele nasceu primeiro.

Por isto, o julgador deve, ao decidir, promover um espaço concentrado e vigoroso para que a sua sentença não esteja, tão somente, restrita à glacialidade exclusiva do direito Positivo: dura lex, sede lex. O direito é uma obra de arte inacabada, que, para a sua expressividade estética, exige a participação de um sentido de conteúdo de sentimento cordial, o que os gregos, a partir de Aristóteles, passaram a identificar como sendo a equidade.

\section{FILOSOFIA}

Entre as muitas concepções encontradas sobre o tema acima, prefiro aquela que expressa, literalmente, "o amor à sabedoria, como o estudo de problemas fundamentais relacionados à existência, ao conhecimento, à verdade, aos valores morais e estéticos, à mente e à linguagem" (TEICHMAN; EVANS, 1999).

É a busca da causa das causas, a busca da origem das origens. 
"Nota-se um período que envolveu a idade antiga e a idade média, no qual a filosofia teve uma abrangência sobre quase todas as áreas relacionadas à investigação teórica, com destaques às disciplinas completamente abstratas, em que o objeto nuclea fundava-se no ser enquanto ser, além de envolver, também, pesquisas acerca de outros assuntos mais complexos e específicos, entre os quais a queda dos corpos e a catalogação de todos os seres vivos. Já a partir do século XVII, especificamente, vários ramos do conhecimento começaram a se desvencilhar da filosofia passando desta forma a se constituirem em ciências independentes com técnicas e métodos próprios (priorizando, sobretudo, a observação e a experimentação)" (MORENTE, 1980).

"Apesar disso, a filosofia atual ainda pode ser vista como uma disciplina que trata de questões gerais e abstratas que sejam relevantes para a fundamentação das demais ciências particulares ou demais atividades culturais. A princípio, tais questões não poderiam ser convenientemente tratadas por métodos científicos"(HUISMAN; VERGEZ, 1980, p. 155-158).

"A admiração é a verdadeira característica do filósofo. Não tem outra origem a filosofia" (PLATÂO, s.d. p.16).

Na mesma linha, afirmava Aristóteles:

"Os homens começam e sempre começaram a filosofar movidos pela admiração" (ARISTÓTELES, [350 E.C. $]^{4}$ ).

É diferenciada das demais ciências porque, ao contrário das outras, os problemas tipicamente filosóficos não podem ser resolvidos por observação e experimentação (MAGEE, 20011, p. 7-9).

O sociólogo e filósofo alemão Georg Simmel $^{5}$ ressaltou esse ponto ao dizer que um dos primeiros problemas da filosofia é o de investigar e estabelecer a sua própria natureza. Talvez a filosofia seja a única disciplina que se volte para si mesma dessa maneira (WIKIPEDIA, 2014).

Platão e Aristóteles concordam em caracterizar a filosofia como uma atividade racional estimulada pelo assombro ou admiração. Mas, para Platão o assombro é provocado pela instabilidade e contradições dos seres que percebemos pelos sentidos. A filosofia, no quadro platônico, seria a tentativa de superar esse mundo de coisas efêmeras e mutáveis e apreender racionalmente a realidade última, composta por formas eternas e imutáveis que, segundo Platão, só podem ser captadas pela razão. Razão que deve ser perseguida pelo julgador contemporâneo.

Dessarte, tem a filosofia o objetivo de administrar o conhecimento universal, não na função de uma soma enciclopédica de tudo o que se dá neste meio, mas no tocante à compreensão dos princípios considerados básicos que envolvem as outras ciências, artes ou ofícios.

Estudos demonstram que depois de Platão e Aristóteles nota-se uma divisão da filosofia em dois modelos, sendo uma teórica e outra prática. A filosofia teórica é regra do conhecimento, a prática é regra do comportamento perante o arbítrio livre. A teórica guarda relação com a teoria e a prática está ligada à práxis. A prática é tida como a busca pela salvação pessoal voltando-se a fé religiosa, ganhando destaque em relação à parte teórica da filosofia, representando, assim, uma forma de viver. Em complemento, registro que o cristianismo exerceu grande influência na moldagem e compreensão da filosofia.

A história ocidental estampa a compreensão de que a filosofia sempre refletiu uma constante preocupação com as questões essenciais para o homem no sentido de sempre oferecer soluções - ao menos respostas - aos problemas que predominavam em cada época. Contudo, o surgimento da era moderna entrou em choque com as bases desta forma de sabedoria tradicional, circunstância que

\footnotetext{
${ }^{4}$ E.C. - Era Comum ou Era Cristã.

${ }^{5}$ Simmel Georg, sociólogo alemão, professor universitário admirado pelos seus alunos, sempre teve dificuldade em encontrar um lugar no seio da rígida academia do seu tempo.
} 
dirigiu aos pensadores a missão de buscar novas formas de conhecimento capaz de sustentar a razão. Razão que sempre deve acompanhar o Julgador, repito.

Há uma afirmação baseada na divisão da filosofia em áreas de investigação específica sendo que em cada área a pesquisa filosófica se dedica à elucidação de problemas próprios. Estas áreas, consideradas tradicionais da filosofia, são a metafísica e a epistemologia. A primeira, a metafísica, cuida da elaboração de teorias que envolvem a realidade e a natureza fundamental de todas as coisas, direcionando uma visão completa do mundo capaz de reunir as mais diversas formas da realidade. "A metafísica tem, como uma subárea, a ontologia (literalmente, a ciência do "ser"), cujo tema principal é a elaboração de escalas de realidade. Nesse sentido, a ontologia buscaria identificar as entidades básicas ou elementares da realidade e mostrar como essas se relacionam com os demais objetos ou indivíduos - de existência dependente ou derivada" (SOLOMON; HIGGINS, s.d.).

A outra, a epistemologia - também conhecida como teoria do conhecimento - é tida como o espaço da filosofia que estuda a natureza do conhecimento, bem como sua origem e seus limites.

Mas, há ainda quem acrescente uma terceira versão neste contexto, a lógica. Esta que trata das estruturas formais do raciocínio perfeito - ou seja, daqueles raciocínios cuja conclusão preserva a verdade das premissas. "Na lógica são estudados, portanto, os métodos e princípios que permitem distinguir os raciocínios corretos dos raciocínios incorretos" (COPI, 1978, p.19).

René Descartes (1596-1650) redirecionou o foco da discussão filosófica para o sujeito pensante. O projeto de Descartes era o de assentar o edifício do conhecimento sobre bases seguras e confiáveis. Para tanto, acreditava ele ser necessário um procedimento prévio de avaliação crítica e severa de todas as fontes do conhecimento disponível, num procedimento que ficou conhecido como dúvida metódica. Segundo Descartes, ao adotar essa orientação, constatamos que resta como certeza inabalável a ideia de um eu pensante: mesmo que o sujeito ponha tudo em dúvida, se ele duvida, é porque pensa; e, se pensa, é porque existe. Essa linha de raciocínio foi celebrizada pela fórmula "penso, logo existo" (cogito ergo sum) (DESCARTES, 1999).

E o Julgador do terceiro milênio pode (e deve) fazer uso da metafísica, quando aplica o princípio da primazia da realidade, valer-se da epistemologia para dominar o conhecimento e conhecer seus limites, da ontologia, por apreciar questões envolvendo a dignidade humana e ainda, da lógica, ao traçar o raciocínio mais acertado: "narra mihi factum dabo tibi ius".

\section{CONCLUSÃO}

O Direito Natural pode funcionar tanto como avaliador moral das leis como também determinar o que as leis querem dizer quando interpretadas. Assim, ele tem como objetivo a bondade e o justo por estar sempre focado no caráter ético das ações.

Santo Tomás de Aquino fala de uma coisa que deve ser adequada ao homem segundo a natureza desta mesma coisa, por onde se deduz que o critério primeiro e fundamental do Direito Natural reveste-se na necessidade de que este sirva ao homem, incondicionalmente.

De outro lado, demonstrando uma crescente, tem-se que no século XX, a filosofia se tornou uma disciplina profissionalizada e assim foi aplicada nas universidades, semelhante às demais disciplinas acadêmicas então existentes. Desse modo, tornou-se também menos geral e mais especializada.

“A filosofia tem se tornado uma disciplina altamente organizada, feita por especialistas para 
especialistas. O número de filósofos cresceu exponencialmente, expandiu-se o volume de publicações e multiplicaram-se as subáreas de rigorosa investigação filosófica. Hoje, não só o campo mais amplo da filosofia é demasiadamente vasto para uma única mente, mas algo similar também é verdadeiro em muitas de suas subáreas altamente especializadas.”( SOAMES, 2003, p.463).

De fato, a Filosofia tem ocupado um espaço que sempre lhe pertenceu em todas as áreas, com destaque ao mundo jurídico quando das manifestações judiciais contemporâneas, embora, ainda com certa timidez.

Entretanto, como já dito, nota-se uma crescente observada no Judiciário que busca firmar ainda mais a sua função institucional de dizer o direito, como Estado-Juiz, que traz entre outras justificativas a de que a Filosofia, como forma de procura pelo saber, resta como uma maneira racional para se contrapor a um modelo rígido e estático que não está encontrando guarida na dinâmica que a nós todos envolve.

Pensemos!

\section{REFERÊNCIAS}

ARISTOTELES. Metaphysics. Tradução W.D. Ross.Written 350 B.C.E. Disponível em: http://classics.mit.edu/Aristotle/metaphysics.1.i.html Acesso em: 15 mar. 2014.

COPI, I. M. Introdução à lógica. 2. ed. São Paulo: Mestre Jou, 1978. p. 19.

DESCARTES, R. Discurso do Método. 4a . parte.- Cottingham, JDescartes. São Paulo:Unesp, 1999. p. 24.

FINNIS, John. Lei Natural: or que chamar de "lei"? Por que dizê-la "natural"? Tradução de Magda Lopes. In: CANTO-SPERBER, Monique. Dicionário de ética e filosofia moral v. 2. São Leopoldo: Unisinos, 2003. p. 36-42.

HERVADA, Javier. Lições propedêuticas de filosofia do Direito. Tradução Elza Maria Gasparotto. Revisão técnica Gilberto Callado de Oliveira. São Paulo: WMF Martins Fontes. 2008.

HUISMAN, DENIS; VERGEZ, ANDRÉ. Curso moderno de filosofia: introdução à filosofia das ciências. Rio de Janeiro: Livraria Freitas Bastos, 1980. p. 155-158.

MAGEE, B.. História da filosofia. São Paulo: Loyola, 2001. p. 7-9.

MORENTE, M. G. Fundamentos de filosofia: lições preliminares. São Paulo: Mestre Jou, 1980.

NADER, P.. Introdução ao Estudo do Direito. 23. ed. Rio de Janeiro: Forense, 2003. p. 368.

PENSADOR. Frases de Albert Einstein. [1879-1955?]. Disponível em:

http://pensador.uol.com.br/frases_de_albert_einstein/. Acesso em: 13 mar. 2014.

PLATÃO. Versão eletrônica do diálogo platônico. Minhateca. Disponível em: http://minhateca.com.br/SrMonteiro83/Documentos/LIVROS/Filosofia+oriental/Vers*c3*a3o+eletr*c3*b 4nica+do+di*c3*a1logo+plat*c3*b4nico+*e $2 * 80 * 9 c$ Teeteto*e $2 * 80 * 9 \mathrm{~d}, 45334604$.pdf Acesso em: 15 mar. 2014. 
ROTARY Internacional. Rotary Club de Guimarães. Civismo é preciso. 2 jun. 2005. Disponível em: http://www.rotaryclubguimaraes.com/index.php?option=com_content\&id=1267\%3Acivismo-epreciso\&Itemid=614 Acesso em: 13 mar. 2014.

SILLS, D.L. (ed.). Natural Law. International Encyclopedia of the Social Sciences. New York, 1968, tradução de SGARBI, Adrian. Rio de Janeiro: Lumen Juris, 2007.

SOAMES, S.. Philosophical analysis in the twentieth century. Princeton: Princeton University Press, 2003. v. 2. p. 463.

SOLOMON, R. C.; HIGGINS, K. M. The big questions: a short introduction to philosophy. p.7.

Disponível em: http://www.amazon.com/The-Big-Questions-Introduction-Philosophy/dp/0495595152 . Acesso em: 15 mar. 2014.

TEICHMAN, J.; EVANS, K. C. Philosophy: a beginner's guide. 3. ed. Oxford: Blackwell, 1999.

WIKIPEDIA. Direito natural. Liberalismo.[1776?]. Disponível em :

http://pt.wikipedia.org/wiki/Direito_natural . Acesso em: 25 mar. 2014.

WIKIPEDIA. Consciência (Moral). Disponível em:

http://pt.wikipedia.org/wiki/Consci\%C3\%AAncia_(moral). Acesso em: 25 mar. 2014.

WIKIPEDIA. Epístola aos Romanos. Disponível em:

http://pt.wikipedia.org/wiki/Ep\%C3\%ADstola aos Romanos Acesso em: 25 mar. 2014.

WIKIPEDIA. Georg Simmel. Disponível em: http://pt.wikipedia.org/wiki/Georg_Simmel . Acesso em: 15 mar. 2014.

WIKIPEDIA. Hugo Grócio. Disponível em: http://pt.wikipedia.org/wiki/Hugo_Gr\%C3\%B3cio Acesso em: 13 mar. 2014.

WIKIPEDIA. Ludwig Wittgenstein. Disponível em: http://pt.wikipedia.org/wiki/Ludwig_Wittgenstein Acesso em: 13 mar. 2014.

WIKIPEDIA. Paulo de Tarso. Disponível em: http://pt.wikipedia.org/wiki/Paulo de Tarso . Acesso em: 25 mar. 2014. 